\title{
Does Access to Modern Marketing Channels Improve Dairy Enterprises' Efficiency? A Case Study of Punjab, Pakistan
}

\section{Sana Sadaf* and Khalid Riaz ${ }^{* *}$}

\begin{abstract}
The main objective of this study is to investigate how access to modern marketing channels impacts the efficiency of dairy enterprises. Using data on dairy farms in central Punjab (Sargodha), we carry out a nonparametric data envelopment analysis to measure their technical and scale efficiencies. The results show that, for the sample dairy enterprises, the mean technical efficiency under variable returns to scale was 0.89 while scale efficiency was 0.94 . The results of a follow-on regression analysis support the hypothesis that the access to modern marketing channels, where payment for fresh milk is based on measured milk quality (fat content), improved efficiency. We find that efficiency is positively affected by the size of dairy operations, and negatively by the size of operational land area. Moreover, dairy enterprises with smaller herds tend to operate at a suboptimal scale, possibly due to credit and/or land constraints.
\end{abstract}

Keywords: Dairy, marketing, Punjab, Pakistan.

JEL Classification: C14, M31.

\section{Introduction}

The agricultural sector plays a significant role in Pakistan's economic development; the sector contributed 21.9 percent to the country's gross domestic product (GDP) in 2007/08. Livestock is the single largest subsector within agriculture, accounting for roughly 52 percent of agricultural value-added (Government of Pakistan, 2008). In Pakistan, about 30-35 million people are engaged in livestock-related activities, and 30-40 percent of their income is generated from these activities (Riaz, 2008).

The dairy subsector is in the process of being commercialized, although the bulk of production still takes place at millions of

\footnotetext{
* Graduate Student of Economics, University of Sargodha, Pakistan.

** Professor, Department of Management Sciences, COMSATS Institute of Information Technology, Islamabad, Pakistan.
} 
geographically dispersed farms. Milk supply chains involve various marketing intermediaries, ranging from milk collectors known locally as dodhis ${ }^{1}$ who dominate traditional marketing channels, to large commercial dairy processing firms that procure milk through modern marketing channels, and sell packaged UHT-treated milk and other milk products produced in their own plants.

The milk marketing system in Pakistan is unregulated. There are significant differences in terms of adherence to food safety standards and milk quality (e.g., fat content) collection through traditional versus modern marketing channels. In the case of the former, unrefrigerated milk may sometimes be moved over considerably long distances and during hot weather. It is not packaged at any stage of the supply chain and is of highly variable quality. ${ }^{2}$ Moreover, to prevent it from spoiling during transportation, traditional market intermediaries may add to it various chemicals or ice made from water which is unfit for human consumption.

On the other hand, the commercial dairy firms that operate in modern marketing channels have typically established cool chains with chillers located in their procurement areas. Moreover, the milk quality, including fat content, is tested at each stage during transportation to ensure adherence to food safety standards. The prices that farmers receive for fresh milk sold to commercial dairy firms are based on measured milk fat content. ${ }^{3}$ However, not all commercial firms procure milk directly from the farmers. Firms with inadequate supply chain infrastructure have chillers in the area but not an elaborate network of village milk collection (VMC) centers. These firms allow traditional dodhis to collect milk from nearby villages and deliver it to their chillers.

From a food safety perspective, it is highly desirable that the bulk of Pakistani milk production moves through supply chains managed by modern marketing channels to ensure food safety and quality standards.

\footnotetext{
${ }^{1}$ Milk vendors who collect milk from farm to farm, and supply it to consumers in nearby towns or sell it to milk shops or merchants who transport the produce to cities farther away.

${ }^{2}$ Some studies have found that milk quality, measured in terms of fat content, depends on the enduse. Milk meant for making khoya, a buttery substance used to make traditional sweetmeats, had the highest fat content while the milk sold to urban teashops had the lowest fat content (Riaz, 2008). These changes occur within the milk supply chain, especially when milk reaches a milk shop or creamery, but not necessarily at the farmers' end. Nevertheless, farmers can influence milk fat content through choice of nutrition regime for their livestock.

${ }^{3}$ Milk procurement centers operated by commercial dairy firms are equipped with portable devices for measuring the milk's fat content. The firm offers one base price-usually for milk with a 6 percent fat content, which is typical of buffalo milk in Pakistan-which is adjusted upward or downward depending on the fat content of the milk sold by each individual farmer.
} 
At present, however, the share of modern dairy firms in the overall milk supply is very small. Roughly, 97 percent of the milk produced is marketed through traditional channels, while the remaining 3 percent is procured and processed by commercial firms (Fakhar \& Walker, 2006). ${ }^{4}$ Among other things, the expansion of modern marketing channels' share in overall milk supply will depend on their competitiveness. ${ }^{5}$ Traditional supply chains have lower overheads as, due to poorly enforced food safety regulation by the government, they do not invest in the supply chain infrastructure needed to preserve the quality of fresh milk.

To a considerable extent, therefore, the competitiveness of modern supply chains vis-à-vis their traditional counterparts depends on the former's ability to raise productivity. Some large dairy firms, including a vertically integrated dairy cooperative, provide development and extension services to member dairy farmers, which are financed by the profits from sales of UHT milk in urban markets. ${ }^{6}$ However, not all large commercial dairy firms are cooperatives. Most provide little or no extension services support to farmers. They do, however, use pricing regimes that are based on measured milk quality (i.e., fat content).

We argue here that pricing based on measured milk fat content enhances efficiency because farmers respond by improving animal nutrition in an attempt to capture the quality premium, and in general make more judicious use of feed and fodders. We test this hypothesis by comparing the efficiency of dairy farmers who sell milk both through modern and traditional marketing channels in Punjab, Pakistan. Our findings provide qualified support for the hypothesis.

Section 2 describes the study area and milk marketing networks. Section 3 presents our methodology for nonparametric data envelopment analysis (DEA), specifies the follow-on econometric model, and describes the data used for the study. This is followed by the study's results and corresponding discussion in Section 4. Finally, Section 5 presents our conclusion and recommendations.

\footnotetext{
${ }^{4}$ In Pakistan, the rate of growth of milk production by the commercial dairy processing industry is greater than that of fresh milk production. Thus, the industry's share has likely increased over time. 5 Traditional supply chains thrive due to the poor implementation of government food safety regulations and consumers' preference for fresh milk and their lack of awareness about its quality.

${ }^{6}$ One example is the Idara-e-Kissan cooperative, which was originally started as a project with support from the German government (Riaz, 2008).
} 


\section{Milk Supply Chains in the Study Area}

Our study area is located in district Sargodha in the west central part of the province of Punjab. According to the official livestock census in 2006 (Government of Pakistan, 2006), Sargodha's livestock population comprised 687,685 buffalos, 574,887 cattle, and about 2 million sheep and goats. The district is divided into six subdistricts called tehsils: ${ }^{7}$ these include Sillanwalli, Bhalwal, Kot Momin, Sargodha (subdistrict), Sahiwal, and Shahpur. According to the district livestock office report (Bashir, 2009), commercial dairy firms procure about 117,000 liters of milk daily from different villages in Sargodha. Nestlé runs the largest set of procurement operations in the area, with a daily collection of 70,000 liters of milk. Other big companies, Noon and Haleeb, each procure over 20,000 liters a day.

In our sample, 43 farmers-30 from Sillanwali and 13 from Kot Momin-out of the 175 selected - sold milk directly to VMC centers of large commercial dairy firms, and received prices based on the measured fat content. The remaining farmers sold milk to traditional dodhis. In some cases, where commercial firms had collection centers in nearby villages, the dodhis supplied the milk they collected from the farmers to commercial firms. In these cases, however, the farmers did not receive prices based on measured milk fat content.

Recently, there has been growing interest in understanding how the existence of modern marketing networks influences dairy farming profitability and efficiency. For example, Riaz (2008) finds that members of Idara-e-Kissan-a vertically integrated cooperative that operates a milk modern supply chain and provides extension services-have had better returns to dairy farming compared to nonmembers. Wasim (2005) look at the responsiveness of Pakistani milk producers to price movements and calculated the elasticities of milk production. Burki and Khan (2008) investigate the impact of modern marketing channels on dairy farms' technical efficiency, using stochastic frontier analysis (SFA). Their main findings are: (1) Providing access to milk supply chain networks increases efficiency, (2) Dairy farms located in milk districts achieve the same output levels while using fewer inputs than farms not located in such districts, (3) Infrastructure is an important determinant of efficiency: farms located farther away from built roads are less efficient but the reverse is true for farms located in a milk district, and (4) Farms with larger herds are more efficient than farms with smaller herds, and the

\footnotetext{
${ }^{7}$ A tehsil is an administrative unit within a district. It usually comprises one main town that serves as the tehsil headquarters, a few smaller towns, and several villages.
} 
positive impact of herd size on efficiency is augmented if the farm is located in a milk district.

The next section reviews various methodological approaches to the measurement of efficiency. We propose using a two-stage semiparametric DEA technique to measure efficiency within a multi-outputmulti- input framework.

\section{Methodology and Data}

As mentioned above, we use a semi-parametric DEA approach to assess the efficiency of dairy farmers with access to different marketing channels. The key advantage of DEA is that it does not involve arbitrary assumptions about functional form (Goncalves, Vieira, Lima, \& Gomes, 2008). Several recent studies have conducted DEAs for agricultural and dairy sectors. Javed, Adil, Javed, and Hassan (2008) use the DEA method to study rice-wheat farming systems in Pakistan; Kulekci (2010) does the same for oilseed sunflower farms in Turkey; Coelli, Rahman, and Thirtle (2002) for rice farming in Bangladesh; Dhungana, Nuthall, and Nartea (2004) for rice farming in Nepal; Rios, and Shively (2005) for coffee growing in Vietnam; and Kamruzzaman, Manos, and Begum (2006) for wheat farming in Bangladesh.

Other studies have estimated the technical efficiency of the dairy sector. Goncalves et al. (2008) use DEA to measure the technical efficiency of dairy farms in Minas Gerais, Brazil. They find that larger farms are more technically efficient, but that this is due to better access to credit, technical support, and training. Smaller farms show increasing returns to scale (IRS), indicating that there is scope for increasing efficiency by adopting the optimal scale of operations.

Jaforullah and Whiteman (1999) have analyzed the technical efficiency of the New Zealand dairy industry. Using DEA, they find the mean technical efficiency (variable returns to scale [VRS]) to be 89 percent and scale efficiency (SE) to be 94 percent. More than half of the dairy farms in their sample were operating on a suboptimal scale. In addition, Burki and Khan (2008) use SFA to analyze dairy farms' technical efficiency. Their findings have already been discussed in the previous section.

\subsection{Technical Efficiency}

Farrell (1957) developed the concept of efficiency measurement at the micro-level (as cited in Forsund \& Sarafoglou, 2002). Charnes, 
Cooper, and Rhodes (1978) use Farrell's conceptual framework to measure efficiency by formulating and solving a linear programming problem under the assumption of constant returns to scale (CRS). Banker, Charnes, and Cooper (1984) extend the model to VRS. Such models are known as DEA models.

\subsubsection{Data Envelopment Analysis}

The DEA approach involves determining to what extent the firm's input vector can be contracted while keeping its output level the same (input orientation), or to what extent the output vector can be expanded while keeping input levels the same (output orientation). For this purpose, the firm's actual input-output choices are compared with an external benchmark - the efficient frontier, which is formed by taking linear combinations of the best-practice input-output choices of other firms.

The linear programming technique is used to arrive at measures of potential input savings or output gains. It uses a piece-wise linear efficient frontier to represent technological possibilities. Efficient firms lie on the frontier and inefficient firms lie below it. Computing an individual firm's distance from the frontier is a deterministic exercise since the linear programming formulation does not allow the inclusion of stochastic terms in the model. It is typical for nonparametric DEA to be followed in the second stage by a parametric regression (e.g., based on a Tobit model) to determine the impact of farmer characteristics and environmental variables on technical efficiency.

The idea of comparing a firm's input-output choices against a best-practice frontier is not unique to DEA. There are other econometric approaches, such as SFA, that can achieve the same objective. Apart from postulating a parametric frontier, SFA also assumes that there is a stochastic component represented by the error term. The error is composite and consists of pure white noise as well as a component assumed to be drawn from a half-normal or truncated distribution. The latter can only take negative values and represents the distance of an inefficient firm from the frontier. SFA allows for the inclusion of environmental variables and joint estimation of their impact-along with the identification of frontier function parameters - on technical efficiency.

The main advantage of DEA is that it is nonparametric. That is, the results do not depend on assumptions about the functional form of a firm's unknown technology, or on those regarding the particular 
probability distributions of the stochastic component. The cost of avoiding arbitrary assumptions is that DEA efficiency scores cannot be used for the purposes of statistical inference because they are nonstochastic. By contrast, SFA postulates parametric production technology and a probability distribution for the stochastic error term. ${ }^{8}$ The estimated parameters of the frontier, therefore, have standard errors that can be used to construct confidence intervals and test hypotheses. Both DEA and SFA have been extensively used in the literature on the measurement of technical efficiency. This study employs DEA to analyze the technical efficiency of dairy enterprises.

Under CRS technology, the DEA efficient frontier is a ray from the origin.9 To be on this frontier, a large firm has to maintain the same outputinput ratio as its smaller counterpart. An important consideration is whether, as firms expand, they can realize output increases in the same proportion as increases in inputs. If this is not technically feasible and firms vary greatly in terms of the size of operations, then the use of CRS technology would make larger firms appear more inefficient than smaller firms.

A conical technology set would not be an appropriate choice in such cases. When all firms are not at the optimal scale of operations, CRS technical efficiency measures are confounded by scale efficiencies (SEs) (Coelli, Rao, O' Donnell, \& Battese, 2005, p. 172). The problem can be resolved, however, by postulating VRS technology, which replaces the CRS conical hull with a convex hull that envelops the observed data more tightly.

\subsubsection{The DEA Model}

Following Coelli et al. (2005), the DEA model under VRS used to estimate technical efficiency is specified as follows:

$$
\begin{array}{cl}
\min _{\theta \lambda} \theta & \\
\text { subject to } & -y_{i}+Y \lambda \geq 0, \\
& \theta x_{i}-X \lambda \geq 0, \\
& N 1^{\prime} \lambda=1 \\
& \lambda \geq 0
\end{array}
$$

\footnotetext{
${ }^{8}$ Commonly used functional forms for the efficient frontier include the Cobb-Douglas and translog forms.

${ }^{9}$ The corresponding technology set is a cone.
} 
Here, $y_{i}$ is an $m \times 1$ vector of output of the $i$ th firm, and $x_{i}$ is a $k \times 1$ vector of inputs of the $i$ th firm. $Y$ is an $n \times m$ matrix of outputs for $n$ firms, and $X$ is an $n \times k$ matrix of inputs for $n$ firms. The parameter $\theta$ is the efficiency score of the $i$ th firm. If $\theta$ is equal to 1 , then the firm lies on the boundary of the input possibilities set, and is considered efficient. The parameter $\lambda$ is a vector $(n \times 1)$ whose value is calculated to achieve an optimum solution. These values determine the weights assigned to the input vectors of all other firms that form the piece-wise linear efficient frontier for measuring the efficiency of the $i$ th firm (Goncalves et al., 2008).

The technical inefficiency of a firm may be due partly to its suboptimal scale of operations. DEA technical efficiency scores can be decomposed into pure technical inefficiency and scale inefficiency. This requires computing both CRS and VRS efficiency scores. The difference between the two scores, if it exists, indicates that the firm in question is operating at an inefficient scale. ${ }^{10}$ The SE measure is obtained as the ratio of technical efficiency scores under CRS and VRS, respectively:

$$
\mathrm{SE}=\mathrm{TE} \text { CRS } / \mathrm{TE} \text { VRS }
$$

\subsubsection{Tobit Regression}

To understand the determinants of technical efficiency, we regress our DEA efficiency scores on several explanatory variables, representing farmer and herd characteristics, as well as milk marketing channels. Because the DEA scores necessarily lie between 0 and 1, we use a doubletruncated Tobit regression (see for example, Wossink \& Denaux, 2006). The Tobit model specification is as given below:

$$
y_{i}^{*}=\beta_{0}+\sum_{j=1}^{k} \beta_{i} x_{i}+u_{i} \quad u_{i \sim} I N\left(0, \sigma^{2}\right)
$$

Here, $y_{i}^{*}$, the DEA efficiency score for farmer $i$, is considered a latent variable, and the vector $x_{i}(i=1, \ldots k)$ represents explanatory variables such as farmer and herd characteristics, and other environmental variables, such as access to modern marketing networks, that influence technical efficiency. The observed variable is $y_{i}$ such that

$$
y_{i}=0 \text { if } y_{i}^{*} \leq 0 ; y_{i}=y_{i}^{*} \text { if } 0 \leq y_{i}^{*} \leq 1 ; y_{i}=1 \text { if } y_{i}^{*} \geq 1
$$

\footnotetext{
${ }^{10}$ In a single-output-single-input model, DEA scale inefficiency can be measured roughly as the ratio of average products evaluated at the projection of a firm's input-output combination on the boundary of the VRS convex hull, and at the optimum scale of operations. For more detail and graphical representation, see Coelli et al. (2005, p. 174).
} 


\subsection{Data and Variables Used}

The data for this study was collected through interviews with 175 dairy farmers in the six tehsils of Sargodha district during May-July 2009. In the first stage, villages were selected from Sargodha district. Village selection was purposive because the study's objective was to assess the impact on dairy farmers' technical efficiency of modern marketing networks whose spatial coverage was highly nonuniform within the Sargodha district. Therefore, selecting villages randomly would not have been considered appropriate.

The criteria for village selection included: (i) the existence in the village of a VMC center operated by a commercial dairy firm, (ii) the existence of such centers in the area but not in the village, (iii) proximity to the nearest urban area, and (iv) remoteness of village location from transport and modern marketing networks. In each selected village, a list of farmers was drawn up with the help of local resource persons, and a sample of about 30 farmers was randomly drawn from this list to be interviewed. A secondary list of ten farmers was also prepared. If the originally selected farmer was not available, he was substituted with a farmer from the secondary list.

A detailed questionnaire was developed and pretested before being administered to each dairy farmer. The questionnaire collected information about the farmer's characteristics, the operational details of the farm, the composition of the dairy herd, input use and output decisions, and milk marketing arrangements.

\subsubsection{Variables for DEA}

Our DEA model is constructed using three output and seven input variables. Outputs include: the amount of total milk produced per year, the number of animal units sold per year, and the amount of animal dung produced per year. Inputs comprise: fodder area in the rabi (winter) and kharif (summer) seasons, the amount of feed concentrate used per year, the amount of balanced feed vanda used per year, the annual total value of other miscellaneous feed inputs, ${ }^{11}$ the annual total number of hours worked by permanent hired labor and family labor, the annual user cost of livestock capital, and the number of in-milk and milch animal

\footnotetext{
${ }^{11}$ These included mostly salts as well as fiber in the form of wheat bran and chaff.
} 
units on each farm. ${ }^{12}$ The descriptive statistics for the variables used in the first-stage DEA are given in Table 1.

\subsubsection{Variables for Follow-Up Tobit Analysis}

The second stage of the study focuses on the determinants of technical efficiency. The variables considered are: education, dairy farming experience, operational area of farm, and size of dairy herd (see bottom panel of Table 1). To test the hypothesis regarding efficiency differences between traditional and modern marketing channels, we introduce a dummy variable representing milk marketing through the modern channel, which assumes a value of 1 if the dairy farmer sells milk directly to a modern marketing channel and 0 otherwise.

\section{Table 1: Descriptive Statistics}

\begin{tabular}{lrrrr}
\hline Variables & Mean & Std. dev. & Min. & Max. \\
\hline Outputs & & & & \\
Milk production/ year (l) & $8,468.4$ & $9,020.3$ & 730.0 & $55,115.0$ \\
Animals sold/year (standard livestock & 1.1 & 1.5 & 0.0 & 5.8 \\
units) & & & & \\
Dung produced/year (kg) & $21,712.2$ & $15,563.3$ & $2,190.0$ & $75,737.5$ \\
\hline Inputs & & & & \\
Feed concentrates use/year (kg) & $1,568.7$ & $2,094.9$ & 0.0 & $9,000.0$ \\
Balanced feed (vanda) use/year (kg) & 646.8 & $2,695.3$ & 0.0 & $26,640.0$ \\
Other feed expenditures/year (Rs) & $34,771.8$ & $40,680.6$ & 0.0 & $306,600.0$ \\
Fodder area (rabi, winter) (acres) & 3.1 & 2.7 & 0.06 & 13.0 \\
Fodder area (kharif, summer) (acres) & 3.4 & 3.1 & 0.03 & 16.0 \\
Labor hours per year & $2,863.9$ & $1,414.9$ & 456.3 & 7671.1 \\
In-milk animals in the herd (standard & 3.4 & 2.7 & 0.7 & 14.8 \\
livestock units) & & & & \\
User cost of livestock capital (Rs) & $5,977.7$ & $5,365.3$ & 401.3 & $39,030.0$ \\
\hline Farmer and dairy herd characteristics & & & & \\
Education (years) & 6.3 & 4.7 & 0.0 & 16.0 \\
Experience (years) & 22.7 & 13.9 & 1.0 & 60.0 \\
Operational area (acres) & 10.6 & 10.4 & 0.0 & 52.9 \\
Herd size (standard livestock units) & 11.6 & 8.3 & 0.7 & 41.2 \\
\hline
\end{tabular}

Source: Authors' calculations.

12 The term "in-milk animals" refers to cows and buffaloes in the dairy herd that are currently producing milk. Milch animals are cows and buffaloes regardless of whether or not they currently produce milk. The numbers of both types of animals are converted to standard livestock units. 


\section{Results and Discussion}

\subsection{Technical Efficiency}

Table 2 presents sample average technical efficiency scores under CRS and VRS, as well as SE scores. When we assume technology to exhibit CRS, the average technical efficiency score of the sampled dairy enterprises is 0.84 . Assuming that the reference technology shows VRS yields a sample average efficiency score of 0.89 , which allows the technological frontier to exhibit a less-than-proportionate output increase with a radial expansion in all inputs.

Under the VRS assumption, the inefficient firms are benchmarked against firms of similar size (Coelli et al., 2005). The sample farmers are seen to be 16 percent inefficient on average under more restrictive CRS, but only 11 percent inefficient under VRS. The convexity restriction implied by the VRS assumption leads to lower estimates of inefficiency. Thus, depending on the assumed reference technology, the sampled dairy farmers could reduce input use by 11-16 percent on average, without reducing their output.

Table 2: Technical and Scale Efficiency Scores

\begin{tabular}{lc}
\hline Returns to scale & Technical efficiency score \\
\hline Constant returns to scale & 0.84 \\
Variable returns to scale & 0.89 \\
Scale efficiency & 0.94 \\
\hline
\end{tabular}

Source: Authors' calculations.

The overall scale efficiency of the sampled dairy farms is 0.94 as indicated by the last row of Table 2 . This implies that a 6 percent increase in output is possible on average if optimum-scale operations are adopted. SE seems to be a problem for smaller farmers. This is clearly seen in Table 3 , which presents returns to scale by the size of dairy operations. 
Table 3: Returns to Scale by Size of Dairy Operations

\begin{tabular}{lcc}
\hline Returns to scale & Larger herds & Smaller herds \\
\hline Constant returns to scale & 48.15 & 39.46 \\
Decreasing returns to scale & 40.74 & 10.20 \\
Increasing returns to scale & 11.11 & 50.34 \\
Total & 100.00 & 100.00 \\
\hline
\end{tabular}

Note: Smaller herds are defined as comprising fewer than 20 heads of livestock.

Source: Authors' calculations.

Over half the smaller dairy herds appear to be operating on IRS. These dairy operations could, in theory, increase their efficiency level by expanding their scale of operations. In practice, however, their small landholdings and (possibly) credit constraints do not allow them to maintain an optimum herd size. ${ }^{13}$

\subsubsection{Determinants of Technical Efficiency}

This section explores the determinants of technical efficiency. A number of farmer characteristics and herd characteristics are used as explanatory variables in a Tobit regression with DEA efficiency scores as our dependent variable. The Tobit model is estimated using the QLIM procedure in SAS software. The results are presented in Table 4.

Table 4: Follow-Up Tobit Regression

\begin{tabular}{lcccc}
\hline Parameter & Estimate & Standard error & t-value & p-value \\
\hline Intercept & 1.0572 & 0.0637 & 16.58 & $<0.0001$ \\
Education & -0.0129 & 0.0050 & -2.54 & 0.0112 \\
Dairy farming experience & -0.0019 & 0.0015 & -1.22 & 0.2209 \\
Operational land area & -0.0052 & 0.0023 & -2.25 & 0.0247 \\
Herd size & 0.0091 & 0.0031 & 2.86 & 0.0042 \\
Modern marketing channel & 0.1160 & 0.0504 & 2.30 & 0.0216 \\
\hline
\end{tabular}

Source: Authors' calculations.

\footnotetext{
${ }^{13}$ The landholding constraint is binding for small dairy farmers because livestock in the study area were stall-fed, requiring farmers to allocate land to fodder crops that then compete directly with land allocations for food and cash crops. Some farmers buy fodder from other farmers but because fodder needs to be harvested daily and chopped up before being fed to the animals, such purchases can only take place from nearby farmers. Moreover, credit constraints can prevent smaller farmers from acquiring livestock heads, or force them to liquidate part of the herd to meet emergency expenditures.
} 
Farmers' level of education appears to be negatively related to their technical efficiency scores, and the effect is statistically significant. We include the squared education term to check for nonlinearity with respect to this effect. The squared education term is not significant in any alternative specification. This result is robust whether or not we include a modern marketing channel dummy in the model (see Table A2 in the Appendix). Moreover, the coefficient of the education variable remains negative and significant. The coefficient of dairy farming experience is not significant. This result is also robust to introducing the squared experience term into the model and, moreover, the squared term itself is not statistically significant.

Table 4 suggests that, as a farmer's operational land area increases, dairy farming technical efficiency falls. The coefficient of the operational land area variable is significant at less than 5 percent. This is hardly surprising because farmers with more land tend to grow more cash crops and, in the process, divert labor and managerial resources away from dairy farming operations. Interestingly, an increase in herd size has the opposite effect. The coefficient of the herd size variable is positive and statistically significant at 5 percent. ${ }^{14}$ This corroborates our earlier conclusion that many smaller dairy enterprises operate below optimal scale. We can interpret the positive and statistically welldetermined coefficient of herd size to imply that farmers with larger herds are able to operate near optimum scale, which enhances both their $\mathrm{SE}$ as well as overall technical efficiency.

An important objective of this study was to analyze the impact of access to modern marketing channels on the technical efficiency of dairy farms. Earlier, we hypothesized that access to modern marketing channels-where milk pricing is based on measured milk quality-raises dairy farmers' productivity because it induces them to improve animal nutrition in the attempt to capture a better price.

We test this hypothesis by including in the Tobit regression a dummy variable representing access to modern marketing channels (defined as those through which farmers sell milk directly to the

\footnotetext{
${ }^{14}$ It is possible to argue that herd size is endogenous in the sense that farmers who are more productive are able to raise and maintain larger herds. In the Sargodha district, livestock is mostly stall-fed. Farmers thus have to allocate adequate areas for fodder in each season, which competes with other land uses such as for food and cash crops. Since the land constraint is binding, herd size is determined largely by farm area. While technical efficiency can be changed by better allocation of inputs even in the short run, changes in a farm's operational area can occur only in the long run. Farm size is largely predetermined and, therefore, not endogenously determined by technical efficiency.
} 
collection center of a commercial dairy firm that measures milk fat content and adjusts prices paid accordingly). Farmers selling through other intermediaries are not considered to be accessing a modern channel even if the intermediary subsequently supplies milk to a commercial dairy and is paid a price based on measured fat content. The logic of making this distinction is that only farmers who sell directly to commercial firms are likely to respond to milk quality premiums by adjusting their animals' nutrition. Table 4 shows that the coefficient of the variable representing access to modern marketing channels is positive and statistically significant with a p-value of 0.022 . This provides qualified support to our hypothesis that access to modern marketing channels (that pay dairy farmers based on measured milk quality) raises the technical efficiency of dairy farming.

An important consideration in investigating the relationship between modern marketing channels and technical efficiency is the potential for self-selection. ${ }^{15}$ If the more productive farmers self-select themselves into modern supply chains, then the Tobit regression results reported above could suffer from an endogeneity bias. For a serious endogeneity problem to arise, however, it must be true that self-selection is costless or that at least the transaction costs associated with it are very low.

For our sample, the requirement of zero or low transactions associated with self-selection is not met because of the nonuniform spatial density of modern supply chain networks. ${ }^{16}$ These networks do not extend to all remote areas. Farmers in un-serviced remote areas have no recourse except to sell milk to traditional market intermediaries. Moreover, modern supply chains are also absent from peri-urban areas where the traditional intermediaries, who sell fresh milk in the nearby city, enjoy a cost advantage over large commercial firms that have to first transport fresh milk to their distant processing plants and then ship the processed milk and milk products back to cities and towns.

That the farmer's choice of market intermediary is substantially influenced by the transaction costs associated with milk delivery can be seen in Table 5. The table shows that, almost without exception, farmers who did not report the presence of a VMC point in their village, sell milk to traditional dodhis. Interestingly, some of these villages are located in

\footnotetext{
${ }^{15} \mathrm{We}$ are grateful to an anonymous referee for making this point.

${ }^{16}$ Modern supply chain infrastructure for fresh milk is expensive to build because it requires setting up chillers and establishing village milk collection centers, and there are costs associated with transporting milk over long distances between collection centers and firms' processing plants.
} 
milk districts, but the transaction costs associated with supplying milk to a VMC point located in another village in the district seems to be high enough to cause farmers to opt against self-delivery. ${ }^{17}$

Table 5: Location of VMC and participation in marketing channels

\begin{tabular}{lcrr}
\hline Choice of market intermediary & $\begin{array}{c}\text { VMC centre located in } \\
\text { village }\end{array}$ & Frequency & Percent \\
\hline Modern & Yes & 42 & 100.00 \\
& No & 0 & 0.00 \\
\hline Traditional & Yes & 1 & 0.76 \\
& No & 131 & 99.24 \\
\hline
\end{tabular}

Source: Authors' calculations.

For villages that had VMC points, the reported average distance ranged between 700 and $800 \mathrm{~m}$ or roughly $1.5 \mathrm{~km}$ for a roundtrip. This is the distance a farmer could cover without great difficulty, usually on foot, if delivering milk to a VMC point once or even twice a day. ${ }^{18}$ Table 5 underscores that the location of a VMC point in the village is a necessary condition for participation in a modern marketing channel.

The results reported above suggest that the existence of modern supply chains is linked to a higher technical efficiency score for dairy farming operations. Moreover, the foregoing discussion also suggests that the self-selection problem may not be so severe as to warrant an outright rejection of causality running from modern supply chain networks to higher technical efficiency.

While the results of the Tobit model reported in Table 4 need to be interpreted cautiously, in our view, they provide some weak support to the hypothesis that direct access to modern supply chains could have a positive impact on efficiency. The qualification that access is direct is important because only under this arrangement can the existence of milk quality premiums be adequately signaled to farmers, who would then respond by improving animal nutrition to capture those premiums.

\footnotetext{
${ }^{17}$ The most plausible explanation for this is economies of scale in transportation. An individual farmer's marketable surplus for milk is small. Mobile dodhis collect milk from several farmers at a time and supply it to shops in towns or to modern supply chain collection points located in other villages in the milk district.

${ }^{18}$ This also suggests that farmers who live on deras farther away from the village cannot participate in the modern marketing channel even when the VMC is located in the village.
} 
It is pertinent to mention that, as in our model, Burki and Khan (2008) have also used a dummy variable in their stochastic frontier to represent modern marketing channels. They conclude that building milk supply chains increases the technical efficiency of dairy farms, and our results are consistent with their findings.

\section{Conclusion}

Our results indicate that the average technical and scale efficiency scores of the sampled dairy farms overall are 0.89 and 0.94 , respectively. Smaller herds are more likely to be operating at suboptimal scale. The follow up Tobit analysis of the determinants of technical efficiency provides qualified support for our main hypothesis that (i) access to modern marketing channels (milk is priced by measured fat content) increases technical efficiency; and that (ii) farmers sell milk directly to a modern supply chain's collection point. The mere coverage of an area by modern milk marketing networks does not enhance efficiency per se because indirect sales to modern channels through market intermediaries do not give farmers the incentive to alter animal nutritional practices and try to capture milk quality premium.

We recognize that there are possibilities for at least some farmers in the sample to self-select into modern supply chains. But, in our view, such possibilities are very restricted because of the nonuniform spatial density of modern supply chain networks and the existence of significant transaction costs. Therefore, our findings can be cautiously interpreted as providing some weak support for the hypothesis that direct access to modern supply chains may have technical efficiency-enhancing effects through provision of incentives to improve animal nutrition. Our findings underscore the need for further research on the relationship between productivity and contractual arrangements that involve built-in

price incentives based on monitored milk quality (i.e., testing fat content and perhaps other attributes).

The results also suggest that farmers with larger dairy herds are more technically efficient. However, farms with a larger land area score lower efficiency on average, possibly because they tend to specialize in crop agriculture. Likewise, the efficiency scores are inversely related to farmers' level of education. This counterintuitive result has to be interpreted against the backdrop of a very low education level among the sampled farmers (just over six years, on average). Dairy farming experience does not seem to be significantly related to farmer efficiency. 
This study was limited to the Sargodha district, but its key hypothesis should be tested on a wider scale to draw conclusions for the dairy sector as a whole. Any such endeavor should involve drawing a larger sample that could more adequately represent a richer typology of both modern and traditional supply chains, and variations in agro-climatic conditions. The sampling design should address possibilities for selfselection by dairy farmers into various types of supply chain networks. 


\section{References}

Banker, R., Charnes, A., \& Cooper, W. W. (1984). Some models for estimating technical and scale inefficiencies in data envelopment analysis. Management Science, 39(10), 1261-1264.

Bashir, K. (2009). Livestock office report. Sargodha, Pakistan: District Livestock Office.

Burki, A. A., \& Khan, M. A. (2008). Milk supply chain and efficiency of smallholder dairy producers in Pakistan (Working Paper No. 08-62). Lahore, Pakistan: Centre for Management and Economic Research, Lahore University of Management Sciences.

Charnes, A., Cooper, W. W., \& Rhodes, E. (1978). Measuring the efficiency of decision-making units. European Journal of Operational Research, 2, 429-444.

Coelli, T., Rahman, S., \& Thirtle, C. (2002). Technical, allocative, cost and scale efficiencies in Bangladesh rice cultivation: A non-parametric approach. Journal of Agricultural Economics, 53(3), 607-626.

Coelli, T., Rao, D. S. P., O' Donnell, C. J., \& Battese, G. E. (2005). An introduction to efficiency and productivity analysis. New York, NY: Springer.

Dhungana, B. R., Nuthall, P. L., \& Nartea, G. V. (2004). Measuring the economic inefficiency of Nepalese rice farms using data envelopment analysis. Australian Journal of Agricultural and Resource Economics, 48(2), 347-369.

Fakhar, H., \& Walker, G. (2006). The white revolution: "Dhoodh darya"-White paper on Pakistan's dairy sector. Lahore: Pakistan Dairy Development Company. Retrieved from (http://www.pddc.com.pk/DairyPakistan-Publication.pdf).

Farrell, M. J. (1957). The measurement of productive efficiency [Series A, General]. Journal of the Royal Statistical Society. 120(3), 253-290.

Forsund, F. R., \& Sarafoglou, N. (2002). On the origins of data envelopment analysis. Journal of Productivity Analysis, 17, 23-40. 
Goncalves, R. M. L., Vieira, W. D. C., Lima, J. E. D., \& Gomes, S. T. (2008). Analysis of technical efficiency of milk-producing farms in Minas Gerais. Economia Aplicada, 12(2), 321-335.

Government of Pakistan. (2008). Pakistan economic survey 2007-08. Islamabad: Ministry of Finance.

Government of Pakistan. (2006). Pakistan livestock census 2006. Islamabad: Agricultural Census Organization, Statistics Division.

Jaforullah, M., \& Whiteman, J. (1999). Scale efficiency in the New Zealand dairy industry: A non-parametric approach. Australian Journal of Agricultural and Resource Economics, 43(4), 523-541.

Javed, M. I., Adil, S. A., Javed, M. S., \& Hassan, S. (2008). Efficiency analysis of rice-wheat system in Punjab, Pakistan. Pakistan Journal of Agricultural Science, 45(3), 95-100.

Kamruzzaman, M., Manos, B., \& Begum, A. A. (2006). Economic efficiency of wheat farms in a region of Bangladesh under the input orientation model. Journal of the Asia-Pacific Economy, 11(1), 123-142.

Kulekci, M. (2010). Technical efficiency analysis of oilseed sunflower farms: A case study of Erzurm, Turkey. Journal of the Science of Food and Agriculture, 90, 1508-1512.

Riaz, K. (2008). A case study of milk processing: The Idara-e-Kissan cooperative. Lahore Journal of Economics, 13(1), 87-128.

Rios, A. R., \& Shively, G. E. (2005, July). Farm size and nonparametric efficiency measurements for coffee farms in Vietnam. Paper presented at the annual meeting of the American Agricultural Economics Association, Providence, RI.

Wasim, M.P. (2005). Milk production response in Pakistan. The Lahore Journal of Economics, 10 (1), 105-121.

Wossink, A., \& Denaux, Z. S. (2006). Environmental and cost efficiency of pesticide use in transgenic and conventional cotton production. Agricultural Systems, 90, 312-328. 


\section{Appendix}

\section{Table A1: Descriptive Statistics}

\begin{tabular}{lrrrr}
\hline $\begin{array}{l}\text { Variables } \\
\text { (Units per animal per year) }\end{array}$ & Mean & Standard dev. & Minimum & Maximum \\
\hline Outputs & & & & \\
Milk production (l) & $2,349.19$ & 984.20 & 486.67 & $6,123.89$ \\
Animals sold (standard livestock & 0.44 & 0.75 & 0.00 & 3.84 \\
units) & & & & \\
Dung produced (kg) & $7,626.11$ & $5,207.75$ & $2,190.00$ & $49,840.75$ \\
\hline Inputs & & & & \\
Feed concentrates use (kg) & 493.72 & 519.92 & 0.00 & $2,820.00$ \\
Balanced feed (vanda) use (kg) & 154.19 & 461.08 & 0.00 & $3,000.00$ \\
Other feed expenditures (Rs) & $12,496.41$ & $11,791.87$ & 0.00 & $59,250.00$ \\
Fodder area for rabi (acres) & 1.15 & 1.06 & 0.02 & 6.75 \\
Fodder area for kharif (acres) & 1.24 & 1.10 & 0.01 & 5.50 \\
Labor hours per year & $1,214.21$ & 837.43 & 273.75 & $5,858.25$ \\
User cost of livestock capital (Rs) & $2,357.28$ & $2,169.68$ & 171.46 & $12,240.00$ \\
\hline
\end{tabular}

Note: All figures are in units per in-milk animal per year unless otherwise stated.

Table A2: Tobit Regressions (Alternative Specifications)

\begin{tabular}{lrrrr}
\hline Parameter & Model 1 & Model 2 & \multicolumn{1}{c}{ Model 3 } & Model 4 \\
\hline Intercept & $1.090303^{* * *}$ & $1.1123^{* * *}$ & $1.050695^{* * *}$ & $1.003065^{* * *}$ \\
& $(13.44)$ & $(13.50)$ & $(20.40)$ & $(14.39)$ \\
Education & $-0.028631^{*}$ & $-0.0274^{*}$ & $-0.023620^{*}$ & - \\
& $(-1.94)$ & $(-1.82)$ & $(-1.61)$ & \\
Education & 0.001274 & 0.0012 & 0.001040 & - \\
& $(1.14)$ & $(1.03)$ & $(0.92)$ & \\
Experience & -0.002738 & -0.0025 & - & -0.001502 \\
& $(-0.53)$ & $(-0.48)$ & & $(-0.28)$ \\
Experience & 0.000011 & 0.0000095 & - & 0.000018 \\
& $(0.13)$ & $(0.10)$ & & $(0.20)$ \\
Operational area & $-0.005162^{* *}$ & $-0.0055^{* *}$ & $-0.005956^{* *}$ & $-0.007066^{* *}$ \\
& $(-2.23)$ & $(-2.34)$ & $(-2.52)$ & $(-3.01)$ \\
Herd size & $0.008956^{* *}$ & $0.0095^{* *}$ & $0.009500^{* *}$ & $0.008890^{* *}$ \\
& $(2.80)$ & $(2.91)$ & $(2.91)$ & $(2.73)$ \\
Modern marketing channel & $0.119040^{* *}$ & - & - & - \\
\hline
\end{tabular}

Note: T-values are given in parentheses. Asterisks ***,**, and * indicate 99, 95, and 90 percent significance level, respectively. 